\title{
Selenium Form-Dependent Anti-Carcinogenesis: Preferential Elimination of Oxidant-Damaged Prostate Cancer Cell Populations by Methylseleninic Acid is Not Shared by Selenite
}

\author{
Emily C Chiang1, David G Bostwick ${ }^{2}$ and David J Waters ${ }^{1,3,4 *}$
}

${ }^{1}$ Gerald P. Murphy Cancer Foundation, 3000 Kent Avenue, West Lafayette, IN 47906, USA

${ }^{2}$ Bostwick Laboratories, 4355 Innslake Drive, Glen Allen, VA 23060, USA

${ }^{3}$ Department of Veterinary Clinical Sciences, Purdue University, 625 Harrison Street, West Lafayette, IN 47907, USA

${ }^{4}$ The Center on Aging and the Life Course, Purdue University, 1202 W. State Street, West Lafayette, IN 47907, USA

\begin{abstract}
Selenium has received considerable attention as a cancer preventive agent. But the puzzling, disquieting results of the Selenium and Vitamin E Cancer Prevention Trial (SELECT) have called into question how much is really understood about the biology behind selenium and cancer risk. This predicament should provide researchers with a renewed stimulus for exploring mechanisms of selenium anti-carcinogenesis. One such line of inquiry is homeostatic housecleaning - that selenium can preferentially eliminate DNA-damaged cell populations through apoptosis, consistent with the decreased DNA damage and increased apoptosis observed in the prostate of selenium-replete dogs after receiving additional dietary selenium supplementation. Because growing experimental evidence suggests the anti-carcinogenic effects of selenium on prostatic cells are form-dependent and apoptosis is a DNA damage response, the aim of this research was to determine whether selenite, a form of selenium that induces DNA damage, possesses potent homeostatic housecleaning activity. To test this hypothesis, we exposed human and canine prostate cancer cells to non-cytotoxic concentrations of hydrogen peroxide $\left(\mathrm{H}_{2} \mathrm{O}_{2}\right)$ to create cell populations with higher levels of oxidant-induced DNA damage, and then evaluated the extent to which oxidant damage sensitizes prostate cancer cell populations to selenite-triggered apoptosis compared to apoptosis triggered by methylseleninic acid (MSA), a non-DNA damaging methylselenol precursor we previously showed to have strong homeostatic housecleaning activity. In this brief communication, we report that non-cytotoxic oxidant-induced damage does not sensitize prostate cancer cell populations to selenite-triggered apoptosis. Intensity of apoptosis triggered by MSA in $\mathrm{H}_{2} \mathrm{O}_{2}$-damaged prostate cancer cells was 3 times higher than undamaged cell populations not exposed to $\mathrm{H}_{2} \mathrm{O}_{2}(\mathrm{P} \leq 0.01)$. In contrast, neither human nor canine prostate cancer cells with oxidant-induced damage had a significant increase in intensity of selenite-triggered apoptosis compared to undamaged cells. The divergent results between MSA and selenite in our experiments contribute to a growing catalogue of observations that suggest there are important form-dependent differences in the extent to which selenium can impact the emergence of prostate cancer. By carefully documenting the form-dependent biological effects of selenium and other nutrients, we commit ourselves to more precisely qualifying the implications of laboratory results and to more carefully designing and interpreting the results of large-scale human trials.
\end{abstract}

Keywords: Cancer prevention; DNA damage response; Apoptosis; Carcinogenesis; Nutrition; SELECT; Trace mineral

Abbreviations: FBS: Fetal Bovine Serum; $\mathrm{H}_{2} \mathrm{O}_{2}$ : Hydrogen Peroxide; MSA: Methylseleninic Acid; PARP: Poly (ADP-ribose) Polymerase; SELECT: Selenium and Vitamin E Cancer Prevention Trial

\section{Introduction}

Personalizing nutrition for disease prevention - minimizing the risk for diseases such as prostate cancer by optimizing nutrient intake - remains one of the major challenges that scientists and health professionals face today. Emerging data on the relationship between selenium intake and human health point to a U-shaped dose response, suggesting that more selenium is not necessarily better [1-4]. Moreover, careful evaluation of the relationship between selenium status and cancer risk suggests that the anticancer benefit of selenium supplementation in humans and animals cannot be explained simply by antioxidant protection, because it occurs at selenium levels at which selenium-dependent antioxidant enzymes are already maximized $[3,5-8]$. More than ever before, investigators are motivated to explore new mechanisms of selenium anti-carcinogenesis [9-11].

Our work is pointing to a new idea of how selenium might diminish prostate cancer risk - by sweeping away damaged prostatic cells, rather than by protecting cells from damage. This line of reasoning was set in motion by the results of a randomized feeding trial in dogs, the only non-human species to frequently develop prostate cancer during aging [12]. In that study [8], dietary selenium supplementation lowered prostatic DNA damage but increased apoptosis, leading to the hypothesis that selenium might exert its cancerpreventive effect by selectively increasing apoptosis in the most highly DNA-damaged cells. In order to achieve a significant lowering of DNA damage level in the prostate, selenium would have to preferentially eliminate populations of damaged cells, because a non-selective triggering of apoptosis would not explain the overall reduction in DNA damage observed in the prostate of seleniumsupplemented dogs.

*Corresponding author: David J Waters, Director, Center for Exceptional Longevity Studies, Gerald P. Murphy Cancer Foundation, USA, Tel: +1-765-7751005; Fax: +1-765-775-1006; E-mail: dwaters@gpmcf.org

Received January 20, 2015; Accepted February 18, 2015; Published February 28, 2015

Citation: Chiang EC, Bostwick DG, Waters DJ (2015) Selenium Form-Dependent Anti-Carcinogenesis: Preferential Elimination of Oxidant-Damaged Prostate Cancer Cell Populations by Methylseleninic Acid is Not Shared by Selenite. Vitam Miner 4: 126.

Copyright: (C) 2015 Chiang EC, et al. This is an open-access article distributed under the terms of the Creative Commons Attribution License, which permits unrestricted use, distribution, and reproduction in any medium, provided the original author and source are credited. 
Pursuing this line of reasoning, in a recent paper [13] we documented the ability of selenium to preferentially sweep away damaged cells - a process we call homeostatic housecleaning - using an in vitro assay so that DNA damage level could be more carefully controlled in human and canine prostate cancer cell populations. We showed that non-cytotoxic oxidant-induced damage sensitizes prostate cancer cell populations to apoptosis triggered by methylseleninic acid (MSA), a proximal precursor of methylselenol [14]. Methylselenol production is thought to play an important role in the anti-tumorigenic activity of dietary selenium $[10,15]$. Taken together, our results point to a new way in which selenium might render an aging prostate under oxidative attack more resistant to cancer.

At the same time, work by us and others in the field of selenium and cancer has emphasized that the anticancer effects of selenium may be form-dependent [16-19]. It is plausible that a selenium compound that induces DNA damage might have superior homeostatic housecleaning activity than compounds like MSA that do not induce DNA damage. Here, in this brief research communication, we report our experience testing the hypothesis that selenite, an inorganic form of selenium that induces DNA damage [20], might have stronger apoptosis-triggering activity in oxidant-damaged cell populations. Our results comparing MSA and selenite add meaningfully to a growing body of experimental evidence that reveal mainly divergent effects of these two forms of selenium on prostate cancer cells.

\section{Materials and Methods}

\section{Cell lines and assay conditions}

The human prostate cancer cell line DU-145 was purchased from ATCC (Manassas, VA). The canine prostate cancer cell line TR5P was established in our laboratory from a dog with spontaneous prostatic carcinoma [21]. DU-145 human and TR5P canine prostate cancer cells were maintained in DMEM F-12 (GIBCO, Carlsbad, CA) supplemented with $10 \%$ batch-matched fetal bovine serum (FBS) (Invitrogen, Carlsbad, CA) and RPMI-1640 supplemented with 5\% FBS, respectively. The cell culture condition was $37^{\circ} \mathrm{C}$ with a humidified atmosphere of $5 \% \mathrm{CO}_{2}$ in air. For all experiments, cells were seeded at $50 \%$ confluency 18 hours before introducing treatment.

To create prostate cancer cell populations with non-cytotoxic oxidant damage, cells were exposed to hydrogen peroxide $\left(\mathrm{H}_{2} \mathrm{O}_{2}\right)$ (Malinckrodt, Phillipsburg, NJ) for one hour and then DNA strand breaks were measured by Comet assay [22,23]. Dose-finding studies were used to determine the concentration of $\mathrm{H}_{2} \mathrm{O}_{2}$ that induced noncytotoxic oxidant damage, as previously reported [13]. In DU-145 cells without $\mathrm{H}_{2} \mathrm{O}_{2}$ exposure, $23 \%$ of cells had extensive DNA damage (single strand breaks). One-hour exposure of DU-145 cells to $100 \mu \mathrm{M}$ $\mathrm{H}_{2} \mathrm{O}_{2}$ yielded a cell population in which $90 \%$ of cells had extensive DNA damage $(\mathrm{P}<0.0001)$ but was non-cytotoxic - no significant increase in apoptosis or cell death quantified by Annexin-V-fluorescein and propidium iodide [24,25]. Thus, a dose of $100 \mu \mathrm{M} \mathrm{H}_{2} \mathrm{O}_{2}$ was chosen for experiments with DU-145 cells. In TR5P canine prostate cancer cells, $90 \%$ of cells already had extensive DNA single strand breaks before $\mathrm{H}_{2} \mathrm{O}_{2}$ exposure, whereas only $8 \%$ of cells had extensive DNA double strand breakage. Therefore, double strand break induction was a preferred criterion to select doses of $\mathrm{H}_{2} \mathrm{O}_{2}$ that would significantly increase DNA damage in TR5P cells. Exposure to $400 \mu \mathrm{M} \mathrm{H}_{2} \mathrm{O}_{2}$ for one hour increased the number of cells with extensive DNA damage to $13.5 \%(\mathrm{P}=0.001)$. Doses of $\mathrm{H}_{2} \mathrm{O}_{2}$ exceeding $400 \mu \mathrm{M}$ were cytotoxic to TR5P cells. Thus, a dose of $400 \mu \mathrm{M} \mathrm{H}_{2} \mathrm{O}_{2}$ was chosen for experiments with TR5P cells.
To assay the ability of MSA or selenite to preferentially trigger apoptosis in oxidant-damaged cell populations, cells were washed with PBS immediately after $\mathrm{H}_{2} \mathrm{O}_{2}$ exposure and incubated in fresh complete medium containing methylseleninic acid (MSA) or sodium selenite for 24 hours. Methylseleninic acid was chosen for these experiments because the metabolism of this selenium compound to the antitumorigenic metabolite methylselenol does not require lyases, which are absent in many cell lines $[14,15]$. Dose-finding experiments for MSA and selenite identified concentrations of each selenium compound that enabled useful comparison of apoptosis intensity between oxidantdamaged versus undamaged cell populations. Selenite concentrations exceeding $10 \mu \mathrm{M}$ were not studied, because the level is toxic to humans [26]. Comet assay confirmed that at the concentrations used, exposure to selenite, but not exposure to MSA, induced DNA strand breaks as previously reported [20]. After 24 hours incubation, cells were harvested to determine intensity of apoptosis.

To detect apoptosis in cells, cleaved PARP [27,28] or cleaved caspase-3 $[29,30]$ was measured by immunoblot. Cell lysates from both adherent and detached cells were collected in 1\% Triton X-100 lysis buffer containing protease inhibitors. Protein content was quantified by the Bradford dye-binding assay (Bio-Red Laboratories, Richmond, CA). Fifty $\mu$ g of total protein was used for electrophoresis on $8-12 \%$ mini SDS polyacrylamide gel with Tris-glycine buffer $(25 \mathrm{mM}$ Trizma base, $190 \mathrm{mM}$ glycine, $0.1 \%$ SDS). Proteins were transferred in a semidry condition. Membranes were developed with a chemiluminescence kit (Pierce, Rockford, IL) following the manufacturer's instructions. Primary antibodies for immunoblot detection were purchased from Cell Signaling Technology (Beverly, MA). The detection of cleaved PARP served as an execution marker of apoptosis in DU-145 human prostate cancer cells. For TR5P canine prostate cancer cells, since primary antibody for dog cleaved PARP was not commercially available, cleaved caspase- 3 was chosen as the apoptosis marker. Beta-actin was used as the loading control. Blot intensity was quantitated by Kodak Image Station 440CF with 1D Image Analysis Software (Kodak, Rochester, NY) and expressed in arbitrary units.

\section{Data analysis}

Blot intensity of cleaved PARP and cleaved caspase- 3 was used to determine the homeostatic housecleaning activity of MSA and selenite. To test each selenium compound for homeostatic housecleaning activity (i.e., the preferential elimination of oxidant-damaged cell populations), prostate cancer cells were exposed to non-cytotoxic concentrations of $\mathrm{H}_{2} \mathrm{O}_{2}$ to create cell populations with increased oxidant-induced DNA damage. Then we evaluated the extent to which oxidant damage sensitized prostate cancer cell populations to MSA-triggered or selenite-triggered apoptosis. For DU-145 human and TR5P canine prostate cancer cells, this was determined by comparing the extent to which the observed intensity of selenium-triggered apoptosis in oxidant-damaged cells exceeded an expected value, which was equal to the sum of intensities of basal apoptosis in untreated cells, plus apoptosis induced by $\mathrm{H}_{2} \mathrm{O}_{2}$ alone, and apoptosis induced by selenium alone. Data from three independent experiments were analyzed by two-tailed, independent t-test to compare differences between the effect of selenium treatment on blot intensity of apoptosis markers in oxidant-damaged versus undamaged cells. In this manuscript, the term "undamaged cells" refers to cell populations that were not exposed to $\mathrm{H}_{2} \mathrm{O}_{2}$. A p-value $<0.05$ was considered significant. Data are presented as mean and standard deviation (SD). All statistical analyses were carried out using SAS 9.2 software (SAS Institute, Cary, NC).

\section{Results}

In DU-145 human prostate cancer cells, we evaluated whether the 
intensity of apoptosis triggered by MSA in $\mathrm{H}_{2} \mathrm{O}_{2}$-damaged prostate cells exceeded the sum of the basal apoptosis in untreated cells plus apoptosis induced by MSA alone and $\mathrm{H}_{2} \mathrm{O}_{2}$ alone. Figure 1a shows that MSA at $3 \mu \mathrm{M}$ triggered significantly greater apoptosis (3X increase,

(a) DU-145 Human Prostate Cancer Cells

\begin{tabular}{|c|c|c|c|c|c|c|}
\hline \multirow[b]{2}{*}{$\mathrm{H}_{2} \mathrm{O}_{2}(\mu \mathrm{M})$} & \multicolumn{2}{|c|}{ Control } & \multicolumn{2}{|c|}{ MSA } & \multicolumn{2}{|c|}{ Selenite } \\
\hline & 0 & 100 & 0 & 100 & 0 & 100 \\
\hline $\operatorname{MSA}(\mu \mathrm{M})$ & 0 & 0 & 3 & 3 & 0 & 0 \\
\hline Selenite $(\mu \mathrm{M})$ & 0 & 0 & 0 & 0 & 10 & 10 \\
\hline Intensity & ND & ND & $\begin{array}{r}10.2^{\mathrm{b}} \\
(2.66)\end{array}$ & $\begin{array}{r}31.4^{\mathrm{a}} \\
(0.58)\end{array}$ & ND & ND \\
\hline Lane & 1 & 2 & 3 & 4 & 5 & 6 \\
\hline $\begin{array}{l}\text { Cleaved } \\
\text { PARP }\end{array}$ & \multicolumn{6}{|c|}{$\longrightarrow$} \\
\hline$\beta$-Actin & & & & & & \\
\hline
\end{tabular}

(b) TR5P Canine Prostate Cancer Cells

\begin{tabular}{|c|c|c|c|c|c|c|}
\hline \multirow[b]{2}{*}{$\mathrm{H}_{2} \mathrm{O}_{2}(\mu \mathrm{M})$} & \multicolumn{2}{|c|}{ Control } & \multicolumn{2}{|c|}{ MSA } & \multicolumn{2}{|c|}{ Selenite } \\
\hline & 0 & 400 & 0 & 400 & 0 & 400 \\
\hline $\operatorname{MSA}(\mu \mathrm{M})$ & 0 & 0 & 5 & 5 & 0 & 0 \\
\hline Selenite $(\mu \mathrm{M})$ & 0 & 0 & 0 & 0 & 5 & 5 \\
\hline \multirow[t]{2}{*}{ Intensity } & ND & ND & $\begin{array}{r}18.8^{b} \\
(6.90)\end{array}$ & $\begin{array}{c}55.6^{\mathrm{a}} \\
(8.21)\end{array}$ & $\begin{array}{c}11.1 \\
(9.32)\end{array}$ & $\begin{array}{c}15.3 \\
(7.63)\end{array}$ \\
\hline & 1 & 2 & 3 & 4 & 5 & 6 \\
\hline $\begin{array}{l}\text { Cleaved } \\
\text { Caspase-3 }\end{array}$ & & & $\overline{=}$ & 3 & $=$ & $=$ \\
\hline$\beta$-Actin & & & & & & \\
\hline
\end{tabular}

Figure 1: Apoptosis induced by methylseleninic acid (MSA) or selenite in hydrogen peroxide $\left(\mathrm{H}_{2} \mathrm{O}_{2}\right)$-damaged DU-145 human and TR5P canine prostate cancer cells. After 1-hour exposure with $\mathrm{H}_{2} \mathrm{O}_{2}$ to induce non-cytotoxic DNA damage, cells were washed with PBS and treated with MSA or selenite in complete medium for 24 hours, and then intensity of apoptosis was determined using cleaved PARP and cleaved caspase-3. Cells exposed to assay conditions without $\mathrm{H}_{2} \mathrm{O}_{2}$ or selenium served as comparisons. (a) Protein expression of cleaved PARP in DU-145 human prostate cancer cells exposed to $3 \mu \mathrm{M}$ MSA or $10 \mu \mathrm{M}$ selenite. (b) Protein expression of cleaved caspase-3 in TR5P canine prostate cancer cells exposed to $5 \mu \mathrm{M}$ MSA or $5 \mu \mathrm{M}$ selenite. Blot intensities are expressed as mean (SD) in arbitrary units from three independent experiments. $\beta$-actin, which served as the loading control, shows there was equivalent loading in all lanes (using intensity of untreated cells in Lane 1 as reference, the relative intensity for Lane 2-6 in panel a was 0.99 , $0.98,0.98,0.95,0.98$, respectively; in panel $\mathrm{b}$ the relative intensity for Lane $2-6$ was $0.97,0.99,0.97,0.98,1.01)$. For MSA, homeostatic housecleaning activity is determined by comparing the intensity of apoptosis marker in Lane 4 versus the sum of Lanes 1, 2, and 3. For selenite, homeostatic housecleaning activity is determined by comparing the intensity of apoptotic marker in Lane 6 versus the sum of Lanes 1,2, and 5. Since under the conditions of these experiments there was no apoptosis signal in Lane 1 (there was no significant basal apoptosis in untreated cells) or Lane 2 (there was no apoptosis signal for $\mathrm{H}_{2} \mathrm{O}$ treatment alone because the $\mathrm{H}_{2} \mathrm{O}_{2}$ dose used was intended to be DNAdamaging, but not cytotoxic), the comparison of interest is simplified to Lane 4 vs. Lane 3 for MSA and Lane 6 vs. 5 for selenite. For each cell line within the same selenium treatment group, mean values without a common superscript differ at $P<0.05$. ND: non-detectable.
$\mathrm{P}=0.01)$ in $\mathrm{H}_{2} \mathrm{O}_{2}$-damaged cells than expected. A similar threefold increased intensity of apoptosis triggered by MSA $(5 \mu \mathrm{M})$ was seen in $\mathrm{H}_{2} \mathrm{O}_{2}$-damaged TR5P canine prostate cancer cells compared to undamaged cells not exposed to $\mathrm{H}_{2} \mathrm{O}_{2}(\mathrm{P}=0.004$; Figure $1 \mathrm{~b})$, evidence of preferential elimination of oxidant-damaged cell populations by MSA-triggered apoptosis.

In contrast, apoptosis triggered by selenite was not higher in $\mathrm{H}_{2} \mathrm{O}_{2}$ damaged cells compared with undamaged cells. Non-cytotoxic oxidant damage did not sensitize DU-145 cells to selenite-triggered apoptosis; an increase in apoptosis was not detected by PARP cleavage in either undamaged or $\mathrm{H}_{2} \mathrm{O}_{2}$-damaged DU- 145 cells exposed to $10 \mu \mathrm{M}$ selenite (Figure 1a). In TR5P canine prostate cancer cells, selenite at $5 \mu \mathrm{M}$ induced apoptosis in undamaged cells. However, the intensity of selenitetriggered apoptosis was not significantly higher in cell populations with oxidant-induced damage $(\mathrm{P}=0.18$; Figure $1 \mathrm{~b})$. We concluded that, unlike for MSA-triggered apoptosis, non-cytotoxic oxidant-induced damage does not sensitize prostate cancer cells to selenite-triggered apoptosis.

\section{Discussion}

Prostate cancer is the ultimate product of dysregulated homeostasis within the aging prostate. Through triggering apoptosis, selenium may selectively eliminate DNA-damaged cells, keeping genetic instability low within the prostate, and consequently attenuating carcinogenesis. If this process of preferential elimination of DNA-damaged cell populations - which we have called homeostatic housecleaning [13] - can potentially render the prostate more resistant to cancer, it is important to identify the forms of selenium with the most potent homeostatic housecleaning activity. In this communication, we show that in contrast to methylseleninic acid (MSA), selenite does not preferentially trigger the apoptosis of oxidant-damaged prostate cancer cell populations. The magnitude of apoptosis triggered by selenite was not different between undamaged prostate cancer cell lines and cells after non-cytotoxic damage induced by $\mathrm{H}_{2} \mathrm{O}_{2}$ exposure.

These results add to a growing body of experimental evidence and clinical suspicion that the anti-carcinogenic effects of selenium are form-dependent. For example, supplementation with selenium in the form of selenium yeast significantly decreased prostate cancer incidence in the men of the Nutritional Prevention of Cancer Trial [5]. Yet, in the Selenium and Vitamin E Cancer Prevention Trial (SELECT), no such cancer-protective advantage of selenomethionine was observed; in fact, supplementation of men with the highest baseline selenium status was associated with an increased risk for prostate cancer [4]. These discordant results raise questions whether particular forms of selenium might elicit superior prostatic responses. These highly publicized results have motivated researchers to begin to report their experience with dietary supplementation studies directly comparing selenomethionine and selenium yeast [16,31]. Clearly, this is only a starting point. The interrogation of a broader range of prostatic responses and a more extensive array of selenium compounds are needed to better understand critical differences in the selenium form-dependent effects that may impact cancer risk.

Our initial work on selenium-triggered apoptosis and prostate cancer showed that non-cytotoxic oxidant damage sensitizes cells to MSA-triggered apoptosis [13]. We reasoned that selenite might have even more potent homeostatic housecleaning activity because selenite has been shown to induce DNA strand breaks [32], which might render selenite better equipped than MSA (which does not damage DNA) to trigger apoptosis in prostate cell populations 
Citation: Chiang EC, Bostwick DG, Waters DJ (2015) Selenium Form-Dependent Anti-Carcinogenesis: Preferential Elimination of Oxidant-Damaged Prostate Cancer Cell Populations by Methylseleninic Acid is Not Shared by Selenite. Vitam Miner 4: 126.

after non-cytotoxic $\mathrm{H}_{2} \mathrm{O}_{2}$ exposure. Here, we show this is not so. These discordant results - positive homeostatic housecleaning activity with MSA, negative homeostatic housecleaning activity with selenite - are consistent with previous studies showing these two compounds exert divergent effects on an array of mechanisms of anti-carcinogenesis in prostatic cells as diverse as reactive oxygen species production [33], p53 activation [30,34], cell cycle arrest $[35,36]$, androgen receptor signaling [37,38], matrix metalloproteinase production $[39,40]$, and apoptosis $[28,30,33,35,41]$. Of particular relevance to the results reported here are the findings of $\mathrm{Hu}$ and colleagues [28] that MSA can potentiate apoptosis induced by chemotherapeutic drugs, whereas selenite cannot. Their results from evaluating MSA and selenite in a cancer treatment setting are complemented by our experiments, which evaluate the ability of MSA and selenite to trigger apoptosis following noncytotoxic oxidant damage, suggesting form-dependent effects of selenium may indeed impact the emergence of cancer in a cancer-preventive context - regulating the elimination of damaged epithelial cell populations in the aging prostate exposed to pro-oxidant pressures. Future studies might be directed toward defining the extent to which the expression of specific selenoproteins modulates selenium-induced elimination of oxidant-damaged prostatic cells.

Finally, as scientists and health professionals continue to collectively re-think the role of selenium and other nutrients in cancer prevention, investigators must work to carefully document the form-dependent effects of nutrients. By avoiding a mindset of naïve substitution - seeing one form of nutrient as equivalent to another - we make surer progress toward understanding the implications of our laboratory findings and side-stepping errant assumptions. Moreover, this disciplined approach might help us to avoid potential pitfalls in the design and interpretation of large-scale human trials.

\section{Acknowledgment}

Supported by funding from Bostwick Laboratories awarded to The Gerald P. Murphy Cancer Foundation to investigate selenium and prostate cancer risk.

\section{References}

1. Rayman MP (2012) Selenium and human health. Lancet 379: 1256-1268.

2. Hurst R, Hooper L, Norat T, Lau R, Aune D, et al. (2012) Selenium and prostate cancer: Systematic review and meta-analysis. Am J Clin Nutr 96: 111-122.

3. Chiang EC, Shen S, Kengeri SS, Xu H, Combs GF, et al. (2009) Defining the optimal selenium dose for prostate cancer risk reduction: Insights from the $\mathrm{U}$-shaped relationship between selenium status, DNA damage, and apoptosis. Dose Response 8: 285-300.

4. Lippman SM, Klein EA, Goodman PJ, Lucia MS, Thompson IM, et al. (2009) Effect of selenium and vitamin $E$ on risk of prostate cancer and other cancers: The Selenium and Vitamin E Cancer Prevention Trial (SELECT). JAMA 301: 39-51.

5. Clark LC, Combs GF Jr, Turnbull BW, Slate EH, Chalker DK, et al. (1996) Effects of selenium supplementation for cancer prevention in patients with carcinoma of the skin A randomized controlled trial. JAMA 276: 1957-1963.

6. Combs GF Jr, Gray WP (1998) Chemopreventive agents: Selenium. Pharmaco Ther 79: 179-192.

7. Duffield-Lillico AJ, Reid ME, Turnbull BW, Combs GF Jr, Slate EH, et al. (2002) Baseline characteristics and the effect of selenium supplementation on cancer incidence in a randomized clinical trial: A summary report of the Nutritional Prevention of Cancer Trial. Cancer Epidemiol Biomarkers Prev 11: 630-639.

8. Waters DJ, Shen S, Cooley DM, Bostwick DG, Qian J, et al. (2003) Effects of dietary selenium supplementation on DNA damage and apoptosis in canine prostate. J Natl Cancer Inst 95: 237-241.

9. De Rosa V, Erkekoğlu P, Forestier A, Favier A, Hincal F, et al. (2012) Low dose of selenium specifically stimulate the repair of oxidative DNA damage in LNCaP prostate cancer cells. Free Radic Res 46: 105-116.

10. Yan L, Combs GF Jr (2014) Consumption of a high-fat diet abrogates inhibitory effects of methylseleninic acid on spontaneous metastasis of Lewis lung carcinoma in mice. Carcinogenesis 35: 2308-2313.
11. Kenfield SA, Van Blarigan EL, DuPre N, Stampfer MJ, Giovannuci E, et al. (2015) Selenium supplementation and prostate cancer mortality. J Natl Cancer Inst 107:dju360.

12. Waters DJ, Wildasin K (2006) Cancer clues from pet dogs. Sci Am 295: 94-101.

13. Chiang EC, Bostwick DG, Waters DJ (2013) Homeostatic housecleaning effect of selenium: Evidence that noncytotoxic oxidant-induced damage sensitizes prostate cancer cells to organic selenium-triggered apoptosis. BioFactors 39 575-588.

14. Suzuki KT, Kurasaki K, Ogawa S, Suzuki N (2006) Metabolic transformation of methylseleninic acid through key selenium intermediate selenide. Toxicol App Pharmacol 215: 189-197.

15. Ip C, Thompson HJ, Zhu Z, Ganther HE (2000) In vitro and in vivo studies of methylseleninic acid: Evidence that a monomethylated selenium metabolite is critical for cancer chemoprevention. Cancer Res 60: 2882-2886.

16. Waters DJ, Shen S, Kengeri SS, Chiang EC, Combs GF Jr et al. (2012) Prostate response to supranutritional selenium supplementation: comparison of the target tissue potency of selenomethionine vs. selenium-yeast on markers of prostatic homeostasis. Nutrients 4: 1650-1663.

17. Abdulah R, Miyazaki K, Nakazawa M, Koyama H (2005) Chemical forms of selenium for cancer prevention. J Trace Elem Med Biol 19: 141-150.

18. El-Bayoumy K (2009) The negative results of the SELECT study do not necessarily discredit the selenium-cancer prevention hypothesis. Nutr Cancer 61: $285-286$

19. Hatfield DL, Gladyshev VN (2009) The outcome of Selenium and Vitamin E Cancer Prevention Trial (SELECT) reveals the need for better understanding of selenium biology. Mol Interv 9: 18-21.

20. Spallholz JE (1997) Free radical generation by selenium compounds and their prooxidant toxicity. Biomed Environ Sci 10: 260-270.

21. Walker-Daniels J, Coffman K, Azimi M, Rhim JS, Bostwick DG, et al. (1999) Overexpression of the EphA2 tyrosine kinase in prostate cancer. Prostate 41 $275-280$.

22. Singh NP, McCoy MT, Tice RR, Schneider EL (1988) A simple technique for quantitation of low levels of DNA damage in individual cells. Exp Cell Res 175 184-191.

23. Waters DJ, Shen S, Glickman LT, Cooley DM, Bostwick DG, et al. (2005) Prostate cancer risk and DNA damage: Translational significance of selenium supplementation in a canine model. Carcinogenesis 26: 1256-1262.

24. Koopman G, Reutelingsperger CP, Kuijten GA, Keehnen RM, Pals ST, et al (1994) Annexin $V$ for flow cytometric detection of phosphatidylserine expression on B cells undergoing apoptosis. Blood 84: 1415-1420.

25. Volate SR, Kawasaki BT, Hurt EM, Milner JA, Kim YS, et al. (2010) Gossypol induces apoptosis by activating p53 in prostate cancer cells and prostate tumor-initiating cells. Mol Cancer Ther 9: 461-470.

26. Yang G, Yin S, Zhou R, Gu L, Yan B, et al. (1989) Studies of safe maximal daily dietary Se-intake in seleniferous area in China. Part II: Relation between Se-intake and the manifestation of clinical signs and certain biochemical alternations in blood and urine. J Trace Elem Electrolytes Health Dis 3 123-130.

27. Duriez PJ, Shah GM (1997) Cleavage of poly(ADP-ribose) polymerase: A sensitive parameter to study cell death. Biochem Cell Biol 75: 337-349.

28. Hu H, Jiang C, Ip C, Rustum YM, Lu J (2005) Methylseleninic acid potentiates apoptosis induced by chemotherapeutic drugs in androgen-independent prostate cancer cells. Clin Cancer Res 11: 2379-2388.

29. Nicholson DW, Ali A, Thornberry NA, Vaillancourt JP, Ding CK, et al (1995) Identification and inhibition of the ICE/CED-3 protease necessary for mammalian apoptosis. Nature 376: 37-43.

30. Jiang C, Hu H, Malewicz B, Wang Z, Lu J (2004) Selenite-induced p53 Ser-15 phosphorylation and caspase-mediated apoptosis in LNCaP human prostate cancer cells. Mol Cancer Ther 3: 877-884.

31. Richie JP Jr, Das A, Calcagnotto AM, Sinha R, Neidig W, et al. (2014) Comparative effects of two different forms of selenium on oxidative stress biomarkers in health men: A randomized clinical trial. Cancer Prev Res 7: 796-804

32. Zhou N, Xiao H, Li TK, Nur-E-Kamal A, Liu LF (2003) DNA damage-mediated apoptosis induced by selenium compounds. J Biol Chem 278: 29532-29537. 
Citation: Chiang EC, Bostwick DG, Waters DJ (2015) Selenium Form-Dependent Anti-Carcinogenesis: Preferential Elimination of Oxidant-Damaged Prostate Cancer Cell Populations by Methylseleninic Acid is Not Shared by Selenite. Vitam Miner 4: 126.

33. Li GX, Hu H, Jiang C, Schuster T, Lu J (2007) Differential involvement of reactive oxygen species in apoptosis induced by two classes of selenium compounds in human prostate cancer cells. Int J Cancer 120: 2034-2043.

34. Smith ML, Lancia JK, Mercer TI, Ip C (2004) Selenium compounds regulate p53 by common and distinctive mechanism. Anticancer Res 24: 1401-1408.

35. Jiang C, Wang Z, Ganther H, Lu J (2002) Distinct effects of methylseleninic acid versus selenite on apoptosis, cell cycle, and protein kinase pathways in DU145 human prostate cancer cells. Mol Cancer Ther 1:1059-1066.

36. De Miranda JX, Andrade FD, Conti AD, Dagli ML, Moreno FS, et al. (2014) Effects of selenium compounds on proliferation and epigenetic marks of breast cancer cells. J Trace Elem Med Biol 28: 486-491.

37. Cho SD, Jiang C, Malewicz B, Dong Y, Young CY, et al. (2004) Methyl selenium metabolites decrease prostate-specific antigen expression by inducing protein degradation and suppressing androgen-stimulated transcription. Mol Cancer Ther 3: 605-611.
38. Gazi MH, Gong A, Donkena KV, Young CY (2007) Sodium selenite inhibits interleukin-6-mediated androgen receptor activation in prostate cancer cells via upregulation of c-Jun. Clin Chim Acta 380: 145-150.

39. Jiang C, Ganther H, Lu J (2000) Monomethyl selenium-specific inhibition of MMP-2 and VEGF expression: Implications for angiogenic switch regulation. Mol Carcinog 29: 236-250.

40. Park JM, Kim A, Oh JH, Chung AS (2007) Methylseleninic acid inhibits PMS stimulated pro-MMP-2 activation mediated by MT1-MMP expression and further tumor invasion through suppression of Nf-kappa B activation. Carcinogenesis 28: 837-847.

41. Jiang C, Wang Z, Ganther H, Lu J (2001) Caspase as key executors of methy selenium-induced apoptosis (anoikis) of DU-145 prostate cancer cells. Cancer Res 61: 3062-3070. 